\title{
LINEAR NEUTRALIZING EPITOPES ON THE PEPLOMER PROTEIN OF CORONAVIRUSES
}

\author{
Willem P.A. Posthumus and Rob H. Meloen \\ Central Veterinary Institute, P.0. Box 65, 8200 AB Lelystad \\ The Netherlands \\ Luis Enjuanes and Isabel Correa \\ Centro de Biologia Molecular (CSIC-UAM), Facultad de Ciencias \\ Universidad Autonoma, Canto Blanco, 28049 Madrid, Spain \\ Anthonie P. van Nieuwstadt and Guus Koch \\ Central Veterinary Institute, Department of Virology \\ P.0. Box 365, 8200 AJ Lelystad, The Netherlands \\ Raoul J. de Groot, Johannes G. Kusters, Willem Luytjes, Willy \\ J. Spaan, Bernard A.M. van der Zeijst, and Johannes A. Lenstra \\ University of Utrecht, Department of Bacteriology, Veterinary \\ Faculty, P.0. Box 80165, 3508 TD Utrecht, The Netherlands
}

\section{Introduction}

Three years ago, we reported a comparison of the primary structures of the $S$ peplomer proteins of three coronaviruses - mouse hepatitis virus (MHV, strain A59), infectious bronchitis virus (IBV, strain M41), and feline infectious peritonitis virus (FIPV, strain 79-1146) - which represent the three antigenic clusters in the coronavirus family (De Groot et al., 1987a, b). A periodicity in the C-terminal part of the $S$ sequence indicated the presence of a coiled-coil structure, which forms the stalk of the peplomer. The nonconserved $\mathrm{N}$-terminal sequence probably forms the bulbous part of the peplomer.

In the work reported here, we used the sequence information to locate epitopes that mediate virus neutralization. We will report the results of an approach that focuses on linear epitopes, i.e., epitopes that depend only on the sequence and not on the native conformation of the protein.

\section{Approach}

The large size of the peplomer proteins (1162 to 1452 residues) clearly prohibits classical methods of synthesizing peptides to search for antigenic sequences. Instead, we used a combination of two methods, prokaryotic expression and PEPSCAN peptide synthesis. Insertion of peplomer cDNA fragments into the prokaryotic expression plasmid pEX (Stanley \& Luzio, 1984) leads to an attachment of a peplomer fragment to the $C$ terminus of a cro- $\beta$-galactosidase hybrid protein. The fragments were generated by restriction enzymes (Correa et al., 1989; De Groot et al., unpublished; Kusters et al., 1989b; Lenstra et al., 1989; Luytjes et al., 1989), by random action of DNase I (Lenstra et al., 1989), or by synthetic oligonucleotides (Kusters et al., 1989b). The antigenicity of the expression products was assayed by Western blotting. With only a few exceptions, antibodies that recognized the peplomer protein on a Western blot also bound to one of the hybrid proteins. 


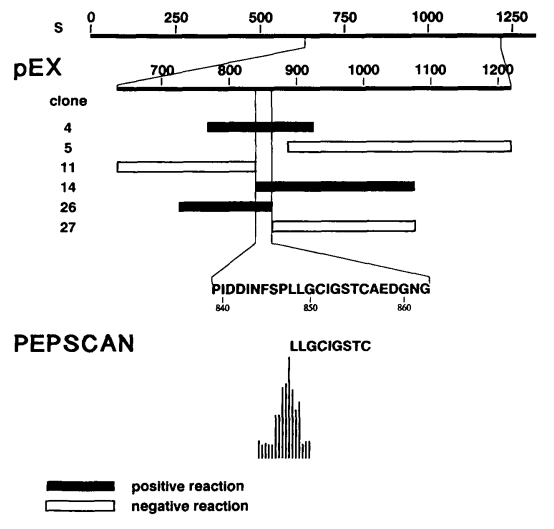

Figure 1. Binding of MAb 19.2 to pEX expression and PEPSCAN products of MHV.

S: The 1324 amino acids of the MHV-A59 peplomer protein.

pEX: Antigenicity of $\mathrm{pEX}$ expression products of clones $4,5,11,14,26$, and 27, which delineate the epitope to the residues 839-862.

PEPSCAN : Analysis of nonapeptides from the $S$ region 839-862, synthesized on a solid support and tested in an ELISA. Vertically is plotted the extinction, measured at $405 \mathrm{~nm}$. The positive binding narrows down the epitope to nine amino acids (Luytjes et al., 1989).

The length of the identified antigenic sequences varied from 6 to 200 residues. Within such an antigenic sequence, the localization of the epitope was narrowed down by PEPSCAN analysis (Geysen et al., 1984). A few antibodies ( usual length of the epitopes.

\section{Mouse hepatitis virus}

Five antigenic sites were identified on the $S$ peplomer protein of MHV (Talbot et al., 1984b; Talbot \& Buchmeier, 1985). Three sites, designated A, $B$, and $C$, are involved in neutralization. Site $A$ was found to be conformation independent (Talbot et al., 1984a) and is thought to be involved in cell-tocell fusion (Collins et al., 1982). Various cDNA restriction fragments were expressed in pEX (Luytjes et al., 1989) and the epitope of the site A-specific $\mathrm{MAb} 19.2$ was located within the sequence $839-862,121$ residues from the $\mathrm{N}$ terminus of the $\mathrm{S} 2$ subunit (Fig. 1, pEX). PEPSCAN analysis of nonapeptides from this region (Fig. 1, PEPSCAN) delineated the epitope within the 848-856 sequence.

Figure 2. Binding of MAbs to pEX expression and PEPSCAN products of IBV. The listed sequence of the $S$ protein from strain D207 (residues 544-574) spans the junction of the two subunits between the residues 545 and 546 . From strains D1466 and M41 the differences with D207 are indicated. The horizontal bars indicate the $S$ sequence fragments synthesized by expression of cDNA fragments from strain D207 (pXD207-Rsa and-XP), D1466 (pXD1466- B, -NB, and

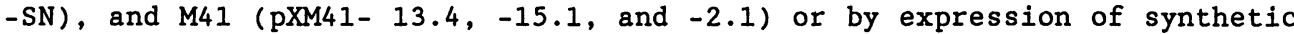
oligonucleotides (pXoligo-1 to -7). Dashed ends indicate continuation beyond the listed sequence. Vertical lines indicate the delineation of the epitopes. The PEPSCAN figure (analysis as described in Fig. 1) shows the binding of MAb 54.5 and 30.6 to nonapeptides from the region 550-578 (Kusters et al., 1989). In the SUMMARY figure dashed ends indicate that epitope boundaries were not located exactly. 

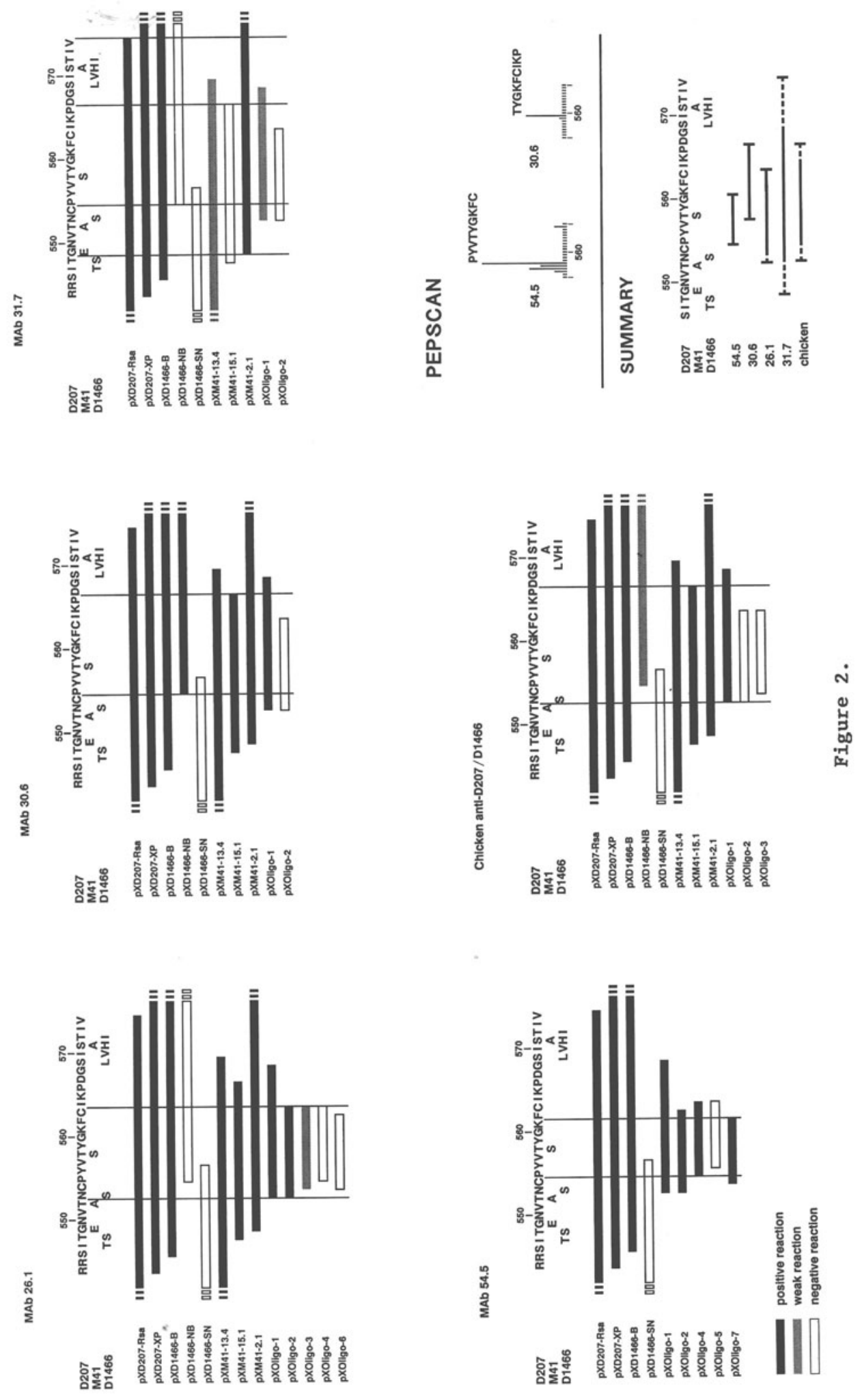
The peplomer protein of IBV contains two subunits - SI consisting of the residues $1-545$ (Kusters et $a 1 ., 1989 a$ ) and $S 2$ containing the residues 546-1180 (Kusters et al.,1989c). The S1 subunit contains most of the epitopes that are involved in neutralization (Cavanagh et al., 1986). By mutual competition of monoclonal antibodies, Koch et al., (1986, 1989) identified four antigenic sites. Three sites, located on S1, are conformation-dependent and induce the serotype-specific neutralizing response. The fourth site (site $D$ ) is located on S2; judged from the recognition of the antigen on Western blots it is conformation-independent. Antibodies specific for site $D$ are not serotype-specific and have a weak but significant neutralizing activity (Koch et al., 1986, 1989). Further, Lenstra et al. (1989) reported that this site is recognized strongly by rabbit, mouse, and chicken antisera.

Restriction enzyme fragments as well as random DNase fragments from IBV strain M41 were used to generate hybrid proteins in pEX (Lenstra et al., 1989 ) and to locate site $\mathrm{D}$ within the $37 \mathrm{~N}$-terminal residues from S2. Subsequently, Kusters et al. (1989b) made a detailed map of the site $D$ epitopes by testing the antigenicity of (i) expression products of cDNA fragments from the strains D207, M41, and D1466; (ii) expression products of synthetic oligonucleotides that encoded the epitope sequence (Fig. 2); and (iii) peptides of different lengths synthesized by the PEPSCAN method. This dissection of the antigenic site revealed the location of overlapping epitopes with lengths varying from 6 to at least 17 residues (Fig. 2, SUMMARY).

Despite extensive sequence divergence in both the S1 and the S2 subunits, the antigenic sequences has been conserved among the different serotypes (Kusters et $a 1 ., 1989 \mathrm{~b}, \mathrm{c})$. Antibodies specific for site $D$ bound to denatured virus, to pEX expression products, and to synthetic peptides. This indicates a segmental mobility on the peplomer surface (Westhof et al., 1984). Presumably, the same mobility is essential for a specific molecular recognition during one of the stages of the virus life cycle.

Transmissible gastroenteritis virus and feline infectious peritonitis virus

Transmissible gastroenteritis virus (TGEV) and FIPV, both representatives of the third antigenic cluster, are generally recognized by the same antibodies. Three groups of investigators (Correa et al., 1988; Delmas et al., 1986; Garwes et a1., 1986) have inventoried the antigenic sites on the TGEV peplomer protein, using mutually competing monoclonal antibodies. For the sake of clarity we designated the sites found by Correa et al., (1988) and Delmas et al., (1986) by roman numerals (Table 1). Sites I and V contain most determinants mediating virus neutralization. The monoclonal antibody COR5 raised against FIPV (S.A. Fiscus, unpublished) neutralized both FIPV and TGEV and probably bound to a sixth antigenic site.

Antibodies specific for site I did not bind to any pEX products or peptides. Monoclonal antibody 1D.B12, which is specific for site II, can discriminate between TGEV and the closely related porcine respiratory coronavirus (PRCV) and bound to a hybrid protein from a PEX-TGEV recombinant containing the 1-

Table 1. Noncompetitive groups of MAbs directed against TGEV.

\begin{tabular}{|c|c|c|}
\hline This paper & Correa et al., 1988. & Delmas et al., 1986. \\
\hline I & $\mathbf{A}$ & $\mathbf{A}$ \\
\hline II & B & D \\
\hline III & C & \\
\hline IV & D & C \\
\hline $\mathbf{v}$ & & B \\
\hline
\end{tabular}




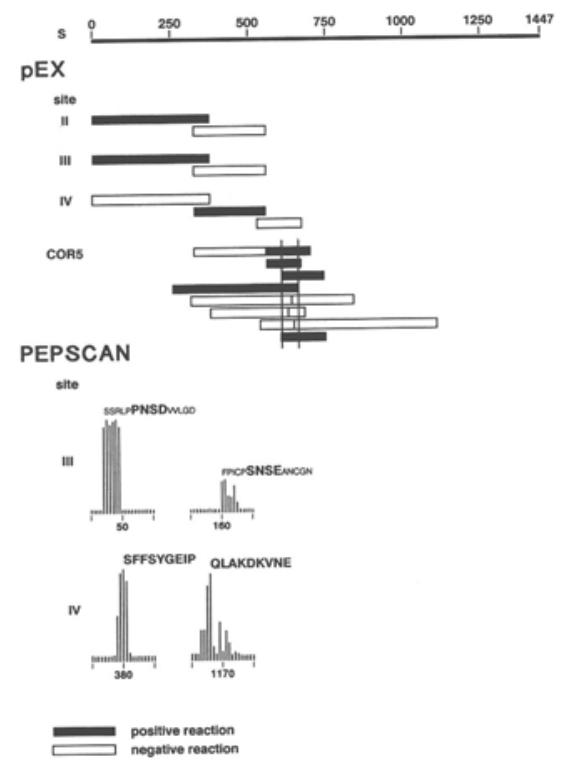

Figure 3. Binding of MAbs to TGEV/pEX and PEPSCAN products.

S : The 1447 amino acids of the TGEV peplomer protein.

pEX: Antigenicity of MAbs of group II, III, and IV with pEX expression products of CDNA clones (TGEV: Correa et al., 1989; FIPV: De Groot et al., unpublished).

PEPSCAN: Analysis is as described in Fig 1. For MAbs of site III the common amino acids from the recognized nonapeptides from the regions $40-60$ and 140-160 are indicated in bold. For MAb 57.57, a representative for MAbs of site IV, the sequence of the most antigenic nonapeptide from the regions 370-390 and 1160-1180 (Posthumus et al., 1989) is indicated.

378 sequence (Correa et al., 1989), but not to any fragment of the sequence 326-1449 (Fig. 3, pEX). This indicates a location of the epitope within the N-terminal region 1-325. Because the PEPSCAN pattern derived with nonapeptides from the TGEV peplomer sequence was inconclusive (not shown), the epitope is probably longer than nine residues. Site III is not involved in neutralization and cross-reacts with components of nonimmune porcine serum (Correa et al., 1988). Recognition by MAbs, specific for site III, of pEX hybrid proteins and PEPSCAN peptides (Fig. 3) led to the identification of the tetrapeptide motive $\mathrm{P} / \mathrm{S}-\mathrm{N}-\mathrm{S}-\mathrm{E} / \mathrm{D}$, which occurs not only twice in the peplomer protein (residues 49-52 and 165-168) but also in several serum proteins (Posthumus et $a 1 ., 1989 \mathrm{~b}$ ). Thus, the epitope mapping may explain the cross-reaction with serum components.

Site IV is recognized by neutralizing as well as non-neutralizing monoclonal antibodies (Delmas et a1., 1986; Correa et al., 1988; Van Nieuwstadt et al., 1989). MAb 57.57 and all other antibodies specific for site IV recognized nonapeptides around residue 380 (Fig. 3, PEPSCAN). Only neutralizing antibodies specific for site IV bound to a second group of peptides around residue 1180 (Posthumus et a1., 1989). However, only the 380 region was antigenic when tested as part of a pEX hybrid protein. Further, antisera against a peptide with the sequence 377-390 were positive in a virus-ELISA and TGEV neutralization assay, but antisera against a 1176-1184 peptide were not (Posthumus et al., 1989). We propose that site IV is complex and that the recognition of nonapeptides from the region 1176-1193 (and nonapeptides with a similar amino acid composition) reflects the surrounding of the region 380-388 in the tertiary structure of the peplomer. Thus, the neutralizing MAbs specific for site IV may bind to a linear part of a discontinuous epitope. 
The epitope of COR5 was located in the region 607-660 (in the numbering of the TGEV sequence) by using pEX-FIPV and pEX-TGEV recombinants (Fig. 3, pEX; De Groot, unpublished). The region encoding this epitope appeared to encompass three restriction enzyme cleavage sites at positions corresponding to the amino acid residues 629,640 and 648 . These data indicate that the linear epitope of COR5 is unusually long and probably can explain the negative results obtained with PEPSCAN peptides.

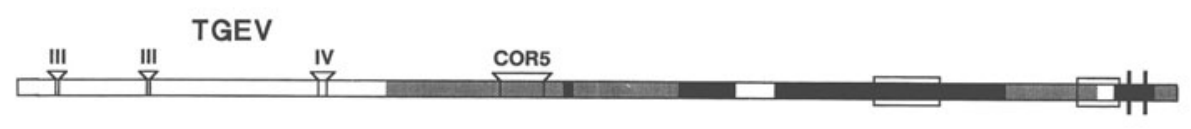

IBV

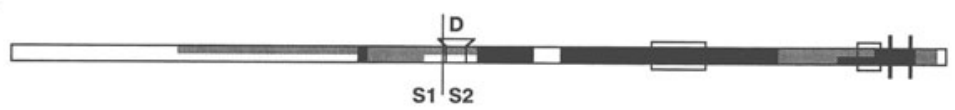

MHV

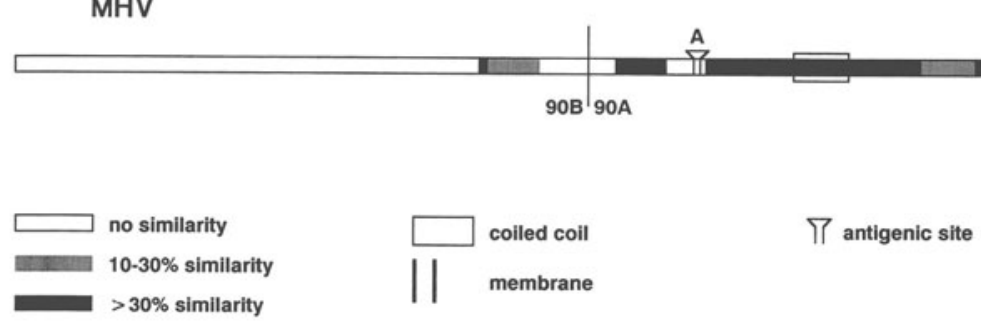

Figure 4. Linear antigenic sites on aligned peplomer sequences.

\section{Survey of linear epitopes of the peplomer proteins}

Fig. 4 shows a schematic alignment of the amino acid sequences (De Groot et a1., 1987a, b) of the peplomer proteins from MHV, IBV and TGEV/FIPV with the locations of the linear epitopes. The length of the epitopes varied from 5 (TGEV site III) to at least 20 (COR5) residues. Antigenic sites appear to be located in regions without or with only moderate sequence similarity. In contrast to the finding with homologous picornaviruses (Rossman et al., 1985), no homology is observed with regard to the locations of the epitopes. For instance, in IBV nearly all linear epitopes of monoclonal antibodies (and most of the linear epitopes of polyclonal antibodies, Lenstra et al., 1989) are mapped in site $D$, but different patterns are observed for MHV and TGEV/ FIPV. If the linear epitopes are located within relatively flexible surface 
loops (Westhof et al., 1984), our observations demonstrate the degree of structural divergence of the peplomer proteins of the different coronaviruses. This divergence is probably caused by differences in host range. It would be interesting to extend these observation to conformation-dependent epitopes. However, this awaits not only the localization of these epitopes by analyzing mutants that escape neutralization, but also a convincing alignment of the regions with a low apparent sequence similarity (de Groot et a1., 1987a).

\section{Acknowledgments}

We thank Wouter C. Puijk and Henk H. Plasman for synthesizing the PEPSCAN peptides, Douwe Kuperus and Hans H. Westra for performing the ELISA assays, Kornelisje A. Zwaagstra and Marc F.D. Baay for constructing of the pEX recombinants and performing the Western blot analyses. Part of this work was supported by a grant from the Netherlands Foundation for Medical Research (Medigon, grant 900-515-02) with financial aid from the Netherlands Organization for Scientific Research (NWO).

\section{Literature cited}

Cavanagh, D., P.J. Davis, D.J.C. Pappin, M.W. Binns, M.E.G. Boursne11, and T.D.K. Brown., 1986, Coronavirus IBV: partial amino terminal sequencing of spike protein S2 identifies the sequence Arg-Arg-Phe-Arg-Arg at the cleavage site of the spike precursor propolypeptide of IBV strain Beaudette and M41. Virus Res. 4:133-143.

Collins, A.R., R.L. Knobler, H. Powell, and M.J. Buchmeier., 1982, Monoclonal antibodies to murine hepatitis virus-4 (strain JHM) define the viral glycoprotein responsible for attachment and cell-cell fusion. Virology 119:358-371.

Correa, I., G. Jimenez, C. Sune, M.J. Bullido, and L. Enjuanes., 1988, Antigenic structure of the E2 glycoprotein from transmissible gastroenteritis coronavirus. Virus Res. 10:77-94.

Correa, I., M.J. Bullido, C. Sune, F. Gebauer, M.F.D. Baay, K.A. Zwaagstra, W.P.A. Posthumus, J.A. Lenstra, and L. Enjuanes., 1989, Correlation between physical and antigenic structure of transmissible gastroenteritis coronavirus E2-glycoprotein. J. gen. Virol., in press.

Delmas, B., J. Gelfi, and H. Laude., 1986, Antigenic structure of transmissible gastroenteritis virus. II. Domains on the peplomer glycoprotein. J. gen. Virol. 67:1405-1418.

Garwes, D.J.,F. Steward, and C.J. Elleman., 1987, Identification of epitopes of immunological importance on the peplomer of porcine transmissible gastroenteritis virus. In: Coronaviruses, Adv. Exp. Med. Biol. 218, p.509-515, M.M.C. Lai and S.A. Stohlman ed., Plenum Press, New York/London.

Geysen, H.M., R.H. Meloen, and S.J. Barteling., 1984, Use of peptide synthesis to probe viral antigens for epitopes to a resolution of a single amino acid. Proc. Natn. Acad. Sci. U.S.A. 81:3998-4002.

De Groot, R.J., W. Luytjes, M.C. Horzinek, B.A.M. van der Zeijst, W.J.M. Spaan, and J.A. Lenstra., 1987a, Evidence for a coiled-coil structure in the spike proteins of coronaviruses. J. Mol. Biol. 196:963-966.

De Groot, R.J., J.A. Lenstra, W. Luytjes, H.G.M. Niesters, M.C. Horzinek, B.A.M. van der Zeijst, and W.J. Spaan., 1987b, Sequence and structure of the coronavirus peplomer protein. In: Coronaviruses, Adv. Exp. Med. Biol. 218, p.31-38, M.M.C. Lai and S.A. Stohlman ed., Plenum Press, New York/London.

Koch, G., L Hartog, A. Kant, D. Van Roozelaar, and G.F. De Boer., 1986, Antigenic differentiation of avian bronchitis virus variant strains employing monoclonal antibodies. Isr. J. Ved. Med. 42:89-97. 
Koch, G., L Hartog, A. Kant, and D. Van Roozelaar., 1989, Antigenic domains on the peplomer protein of avian infectious bronchitis virus: correlation with biological functions. J. gen. Virol., submitted.

Kusters, J.G., H.G.M. Niesters, J.A. Lenstra, M.C. Horzinek, and B.A.M. van der Zeijst., 1989a, Phylogeny of antigenic variants of avian coronavirus IBV. Virology 169:217-221.

Kusters, J.G., E.J. Jager, J.A. Lenstra, G. Koch, W.P.A. Posthumus, R.H. Meloen, and B.A.M. van der Zeijst., 1989b, Analysis of an immunodominant region of avian coronavirus IBV. J. Immunol. 143.

Kusters, J.G., E.J. Jager, and B.A.M. van der Zeijst., 1989c, Sequence evidence for in vivo recombination in avian coronavirus IBV. Submitted.

Lenstra, J.A., J.G. Kusters, G. Koch, and B.A.M. van der Zeijst., 1989, Antigenicity of the peplomer protein of infectious bronchitis virus. Molec. Immun. 26:7-15.

Luytjes, W., D. Geerts, W. Posthumus, R. Meloen, and W. Spaan., 1989, Amino acid sequence of a conserved neutralization epitope of murine coronaviruses. J. Virol. 63:1408-1412.

Posthumus, W.P.A., J.A. Lenstra, W.M.M. Schaaper, A.P.K.M.I. van Nieuwstadt, B.A.M. van der Zeijst, and R.H. Meloen., 1989, Antigenic peptides of the E2 peplomer protein of transmissible gastroenteritis virus. Submitted.

Rossmann, M.G., E. Arnold, J.W. Erickson, E.A. Frankenberger, J.P. Griffith, H.J. Hecht, J.E. Johnson, G. Kamer, M. Luo, A.G. Mosser, R.R. Rueckert, B. Sherry, and G. Vriend., 1985, Structure of a human common cold virus and functional relationship to other picornaviruses. Nature (London) 317:145-153.

Stanley, K.K. and J.P. Luzio., 1984, Construction of a new family of high efficiency bacterial expression vectors: identification of cDNA clones coding for human liver proteins. EMBO J. 3:1429-1434.

Talbot, P.J. and M.J. Buchmeier., 1985, Antigenic variation among murine coronaviruses: evidence for polymorphism on the peplomer glycoprotein, E2. Virus Res. 2:317-328.

Talbot, P.J., R.L. Knobler, and M.J. Buchmeier., 1984a, Western and dot immunoblotting analysis of viral antigens and antibodies: applications to murine hepatitis virus. J. Immunol. Meth. 73:177-188.

Talbot, P.J., A.A. Salmi, R.L. Knobler, and M.J. Buchmeier., 1984b, Topographic mapping of epitopes on the glycoproteins of murine hepatitis virus-4 (strain JHM): correlation with biological activities. Virology 132:250-260.

Van Nieuwstadt, A.P., J. Boonstra, and J. Cornelissen., 1989, Differentiation between transmissible gastroenteritis virus and the related porcine respiratory coronavirus using monoclonal antibodies against transmissible gastroenterites virus. J.Virol., in press.

Westhoff, E., D. Altschuh, D. Moras, A.C. Bloomer, A. Mondragon, A.A. Klug, and H.M.V. Van Regenmortel., 1984, Correlation between segmental mobility and the location of antigenic determinants in proteins. Nature (London) 311:123-126. 